\title{
Torsion of an accessory spleen: a rare case preoperatively diagnosed and cured by single-port surgery
}

\author{
Maiko Ozeki ${ }^{1}$, Mitsuhiro Asakuma ${ }^{1 *}$, Nakai Go², Takeshi Ogura ${ }^{3}$, Yoshihiro Inoue ${ }^{1}$, Tetsunosuke Shimizu', \\ Fumitoshi Hirokawa ${ }^{1}$, Kazuhiro Yamamoto ${ }^{2}$, Michihiro Hayashi ${ }^{1}$, Yoshifumi Narumi ${ }^{2}$, Kazuhide Higuchi ${ }^{3}$ \\ and Kazuhisa Uchiyama'
}

\begin{abstract}
We report a very rare case of acute abdomen caused by torsion of an accessory spleen that was preoperatively diagnosed and cured by single-port surgery. A 31-year-old woman was admitted to our hospital with severe left abdominal pain. Physical examination revealed a left upper quadrant abdominal tenderness with voluntary guarding. Ultrasound demonstrated a well-defined round mass isoechoic to the spleen, measuring $3.0 \mathrm{~cm}$ in diameter in the left upper quadrant adjacent to the spleen. A contrast-enhanced CT scan showed a normally enhanced spleen and a $3.0 \times$ 3.0, hypodense, non-enhancing mass anterior to the spleen with a twisted funicular structure. Torsion of an accessory spleen was suspected, and emergency single-port surgery was performed. During surgery, a rounded violet mass measuring $3.0 \mathrm{~cm}$ in diameter, suggestive of an accessory spleen, with a $1800^{\circ}$ torsion around a long vascular pedicle along the left side of the greater omentum was discovered. The mass was removed and post-operative recovery was uneventful. A review of the literature revealed 26 cases (including ours) of torsion of an accessory spleen in English. Even with the recent advances in radiologic imaging modalities, making a preoperative diagnosis of this is difficult and most cases are diagnosed during laparotomy. This is the first report preoperatively diagnosed and cured by single-port surgery. We decided to start the operation by using a single port, not only for cosmetic reasons for this young female patient, but also for final confirmation of our diagnosis. We believe that single-port laparoscopy is valuable as a diagnostic tool as long as safety is assured for patients with acute abdomen. Although torsion of an accessory spleen is extremely rare, it should be considered in the differential diagnosis of acute abdomen in children and young adults.
\end{abstract}

Keywords: Single-port surgery; Laparoscopic surgery; Surgical glove; Accessory spleen; Acute abdomen; Torsion; Preoperative diagnosis

\section{Background}

Accessory spleen is a congenital anomaly characterized by ectopic tissue separated from the main body of the spleen. It is a relatively common condition that appears in 10 to $30 \%$ of autopsy findings and is usually asymptomatic $[1$, 2]. It is diagnosed incidentally in radiologic examinations carried out for other reasons. However, it seldom gives rise to symptoms and very rarely involves torsion. Its clinical presentation is characterized by a non-specific acute onset or recurrent abdominal pain. Surgical removal leads

\footnotetext{
* Correspondence: sur105@poh.osaka-med.ac.jp

1 Department of General and Gastroenterological Surgery, Osaka Medical

College, 2-7 Daigaku-cho, Takatsuki, Osaka 569-8686, Japan

Full list of author information is available at the end of the article
}

to prompt recovery, but preoperative diagnosis in an emergency situation is extremely difficult, even with modern imaging techniques $[2,3]$.

Herein we report a rare case of an acute torsion of an accessory spleen as an emergency acute abdomen case in a young female patient, that was successfully diagnosed preoperatively. She was subsequently operated on using laparoscopic single-port surgery which has recently been developed. To the best of our knowledge, this is the first acute case of treatment by single-port surgery following preoperative diagnosis.

\section{实 Springer}




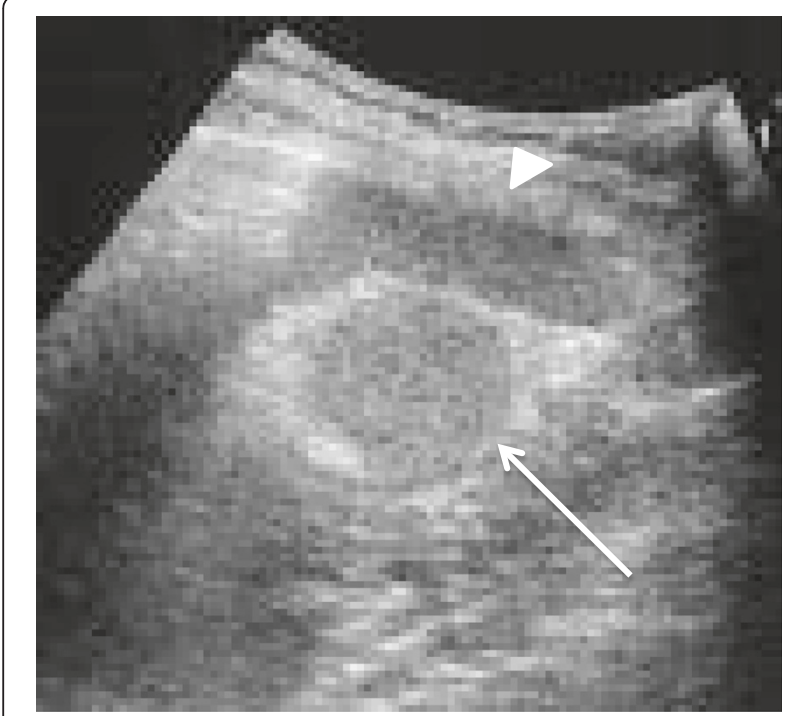

Fig. 1 US findings. US demonstrated a round mass measuring $3.0 \mathrm{~cm}$ (arrow) which was isoechoic to the spleen (arrow head)

\section{Case presentation}

A 31-year-old otherwise healthy woman was admitted as an emergency with intense left abdominal pain. At the time of admission, she had pyrexia $\left(38.5^{\circ} \mathrm{C}\right)$. Physical examination revealed a left upper quadrant abdominal tenderness with voluntary guarding. She was only found to have an elevated level of serum C-reactive protein. Complete blood cell count was unremarkable. Ultrasound (US) demonstrated a well-defined round mass isoechoic to the spleen, measuring $3.0 \mathrm{~cm}$ in diameter in the left upper quadrant adjacent to the spleen (Fig. 1). Contrast-enhanced computer tomography (CT) showed a normally enhanced spleen and a $3.0 \times 3.0$, hypodense, non-enhancing mass anterior to the spleen with a twisted funicular structure (Fig. 2). This twisted funicular structure is more evident in a CT movie (see Additional file 1). Following diagnosis of a highly suspected torsion of an accessory spleen, we operated on her.

The operation was performed by single-port laparoscopy. Surgical glove method with a $1.5-\mathrm{cm}$ umbilical incision was used, as we have previously reported $[4,5]$. Operative findings revealed that the main spleen was normal. A rounded violet mass measuring $3.0 \mathrm{~cm}$ in diameter, suggestive of an accessory spleen, with a $1800^{\circ}$ torsion around a long vascular pedicle along the left side of the greater omentum was discovered. The mass and its pedicle were removed easily, using Surgitie ${ }^{\mathrm{TM}}$ loop (Fig 3). The specimen was retrieved by Endo $\mathrm{Catch}^{\mathrm{Tm}}$. Figure 4 shows the postoperative abdomen.
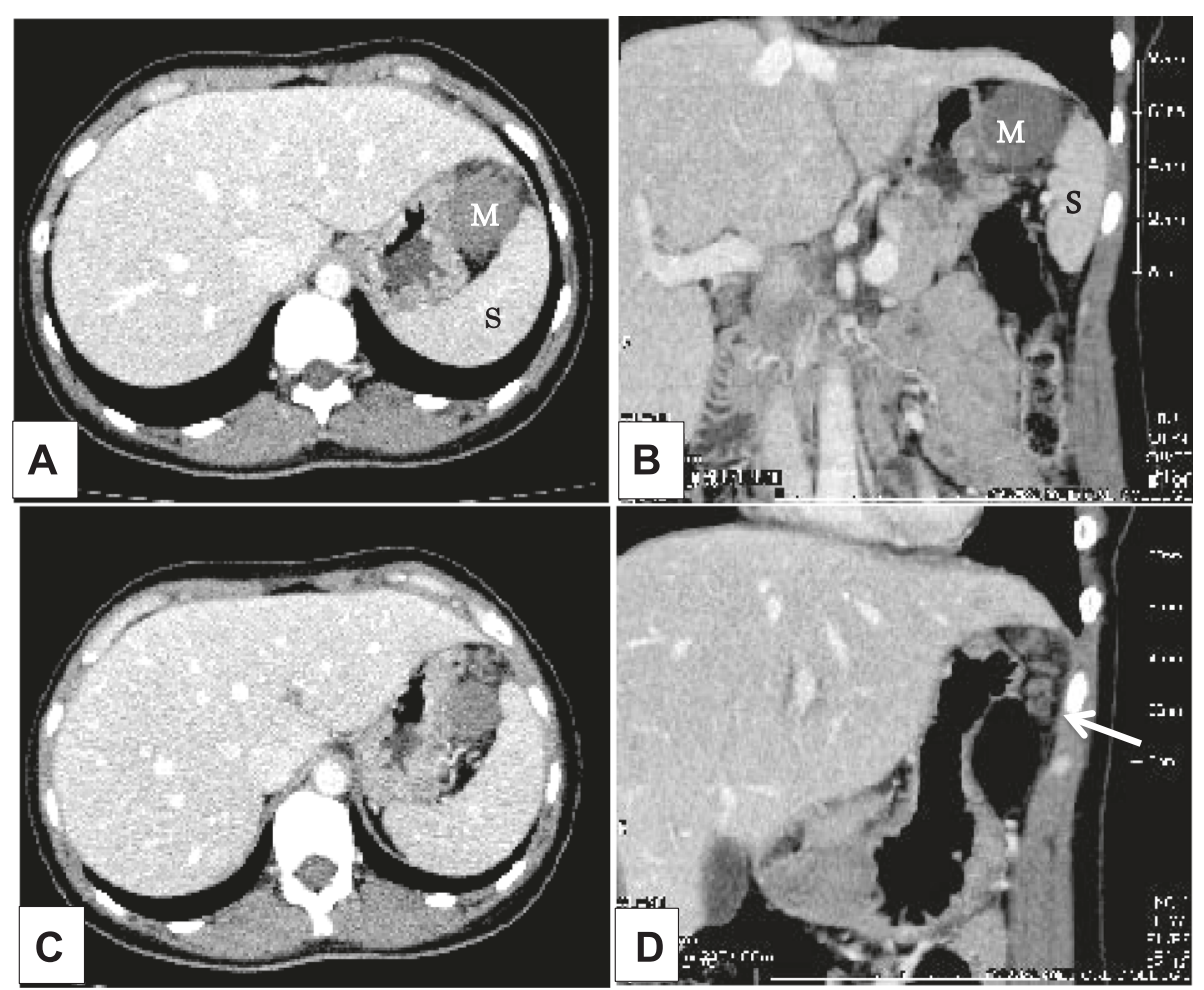

Fig. 2 Axial and coronal contrast-enhanced CT images (a axial, b coronal). This study showed a normally enhanced spleen (S) in left upper quadrant and a non-enhancing mass ( $\mathrm{M}$ ) anterior to the spleen (c axial, $\mathbf{d}$ coronal). The twisted tubular structure (arrow) attached to the mass was detected 

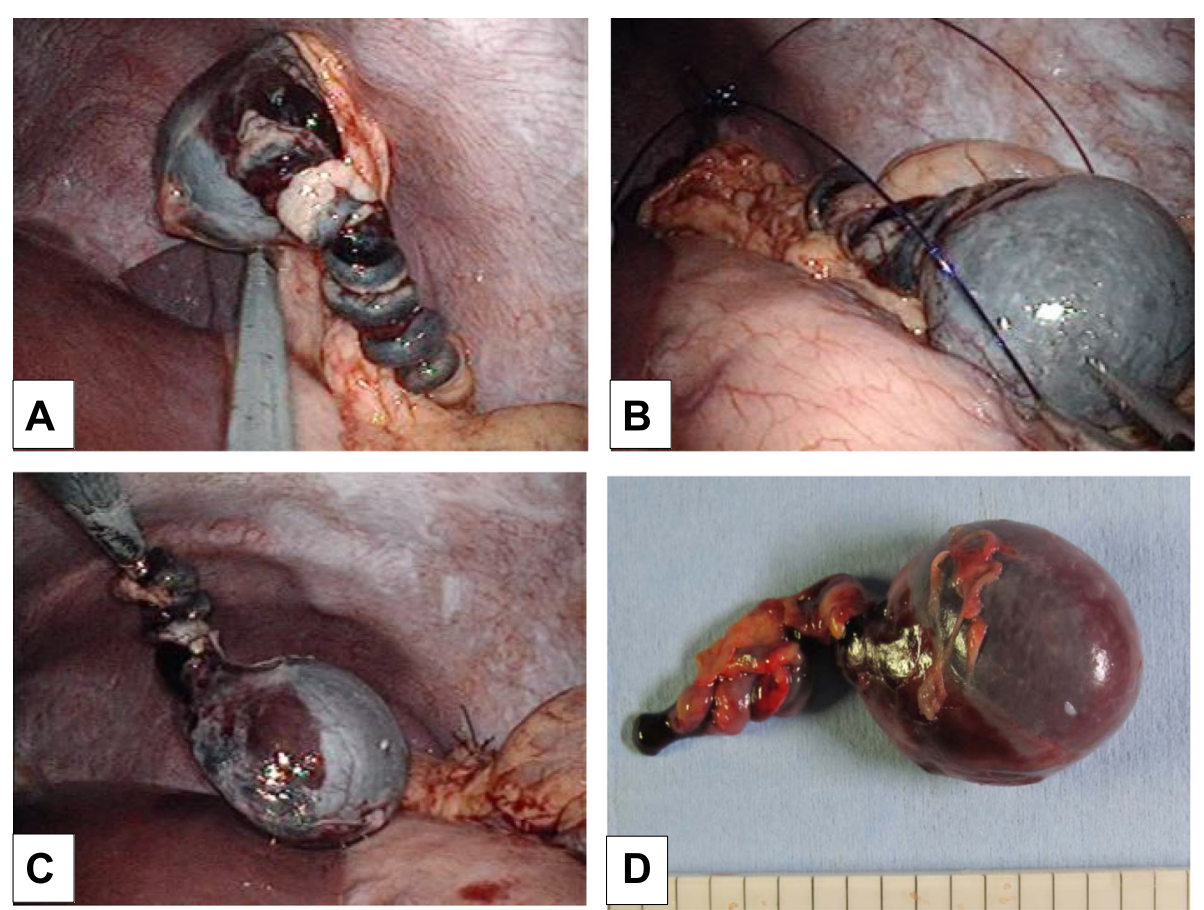

Fig. 3 Intraoperative image highlights. a The rounded violet mass measuring $3.0 \mathrm{~cm}$ in diameter with a $1800^{\circ}$ torsion of its long vascular pedicle. b, $\mathbf{c}$ The mass and its pedicle were removed using Surgitie ${ }^{\mathrm{TM}}$ loop. $\mathbf{d}$ Resected specimen showing an accessory spleen with hemorrhagic infarction and torsion of the stalk

\section{Discussion}

Accessory spleens are found in 10 to $30 \%$ of autopsy findings $[1,2]$. They can be solitary or multiple, are usually asymptomatic and are diagnosed incidentally in radiologic examinations carried out for other reasons. An accessory spleen may be found in various locations from the splenic hilus to the left scrotum, and is caused by the failure of the splenic anlage to fuse during embryogenesis $[3,6]$.

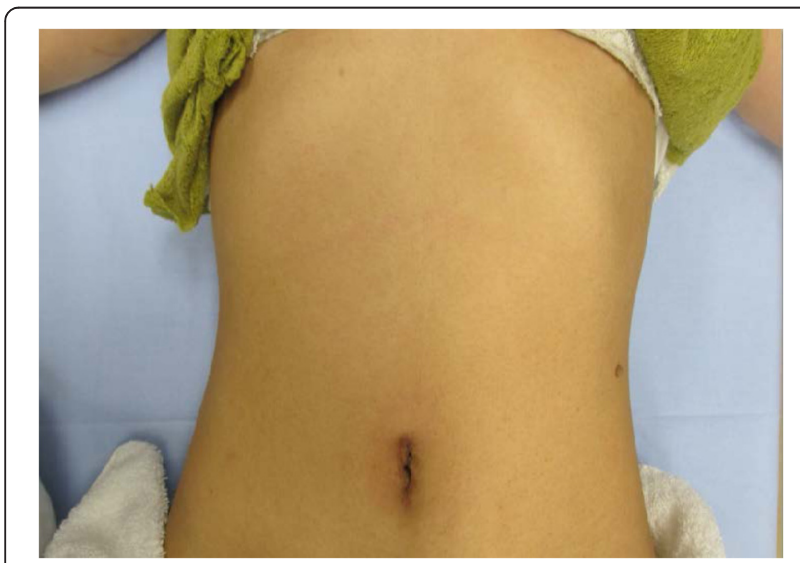

Fig. 4 Post-operative abdomen. It shows a scarless result by single-port laparoscopic surgery
An accessory spleen without an underlying disease such as a haematological disorder or cirrhosis of the liver may occasionally present as an enlarged mass and/or acute abdomen. Emergency surgical intervention may be necessary if these events are accompanied by infarction, haemorrhage or rupture. Torsion of an accessory spleen leading to acute abdomen has been reported in literature since Alexander and Romanes first reported it in 1914 [7]. Torsion of an accessory spleen with resultant infarction may cause an acute abdomen at any age [8]. It is an extremely rare entity that is rarely diagnosed preoperatively $[2,3]$. A review of the literature revealed 26 cases (including ours) of torsion of an accessory spleen after searching for the terms "accessory spleen", "torsion" and "infarction" in PubMed [2, 3, 6-28]. Among the reported 26 cases, in 16 cases, we can find description of the size. The smallest twisted accessory spleen was $2 \mathrm{~cm}$, the largest one was $17 \mathrm{~cm}$ and the median was $6 \mathrm{~cm}$ in diameter. These accessory spleens are originated in various places but mainly at the greater momentum and splenic hilus. Others were at the cecum, jejunum, mesentery and pancreatic tail. Among them, we could not find any relationship between size and tendency of torsion and origin, and also, we could not find a relationship between the length of the pedicle or the origin and torsion. Actually, only three cases were pre-diagnosed and only four cases were successfully treated by laparoscopic surgery (Table 1). This is 
Table 1 Six cases of torsion of the accessory spleen. Case reports of preoperatively diagnosed and/or cured by laparoscopic surgery in 26 cases of torsion of the accessory spleen

\begin{tabular}{|c|c|c|c|c|c|c|c|}
\hline Author & Year & Age & Sex & Size $(\mathrm{cm})$ & Location & Preoperatively diagnosed & Laparoscopic surgery \\
\hline Alexander & 1929 & 35 & $\mathrm{~F}$ & Orange & Greater omentum & 0 & $x$ \\
\hline Mendi & 2006 & 12 & $\mathrm{~F}$ & NA & Splenic hilus & $x$ & $\circ$ \\
\hline Yousef & 2010 & 12 & M & $3.5 \times 2.5 \times 2$ & Greater omentum & $x$ & $\circ$ \\
\hline Lhuaire & 2013 & 66 & M & $3 \times 3 \times 2.5$ & Greater omentum & $\times$ & $\circ$ \\
\hline Bard & 2014 & 20 & $\mathrm{~F}$ & 17 & Spleen & $\circ$ & $\times$ \\
\hline Our case & & 31 & $\mathrm{~F}$ & $3 \times 3 \times 3.5$ & Greater omentum & o & Single port \\
\hline
\end{tabular}

NA not applicable

the first report of preoperatively diagnosed torsion of an accessory spleen cured by single-port surgery. US and CT were performed in some cases. These two diagnostic tools are helpful for detecting a mass and evaluating its size, shape and influence upon surrounding tissues but are less beneficial for making a quantitative diagnosis such as neoplasm, hypertrophy, inflammation or other. Magnetic resonance imaging (MRI) has an advantage over US and CT, however, not only for detecting a mass but also for evaluating its nature and inferring its pathology, despite not always being available in an emergency situation [3, 29]. Angiography and scintigraphy were used in some cases [30]. However, making the correct diagnosis can be difficult even with angiography and scintigraphy because they are not helpful for detecting an accessory spleen when the afferent blood vessels are completely occluded.

In fact, in our case, we made a successful diagnosis using both US and CT findings, which showed an isoechoic mass to the spleen and an avascular mass with twisted pedicle, respectively. In particular, the CT scan clearly showed a twisted pedicle, which was the biggest clue in making our correct diagnosis. Nonetheless, preoperative diagnosis is only hypothetical, even though it seemed correct in our case, and torsion of an accessory spleen is so rare that it is impossible to diagnose with $100 \%$ confidence. We decided to start the operation by using a single port, not only for cosmetic reasons for this young female patient, but for final confirmation of our diagnosis. We are able to say that laparoscopy is a good diagnostic tool for acute abdomen and single-port laparoscopy is an alternative solution for diagnosing acute abdomen because if the diagnosis is different from the preoperative findings, the surgeon can easily convert to conventional laparoscopic surgery by adding as many ports as he/she needs or even switching to open surgery by making an adequate skin incision. In our case, once the diagnosis had been confirmed, we could continue with the accessory splenectomy. As an accessory splenectomy in itself is a simple procedure, the benefits for the patient are clear, i.e. much better cosmetic results and less pain than with open surgery.

\section{Conclusions}

Torsion of an accessory spleen should be considered in the differential diagnosis of acute abdomen in children and young adults. Awareness of this entity and familiarity with typical imaging findings are important. We believe that single-port laparoscopy is valuable as a diagnostic tool, and as long as safety is assured, this method has clear benefits for patients with acute abdomen.

\section{Consent}

Written informed consent was obtained from the patient for the publication of this case report and any accompanying images. A copy of the written consent is available for review by the Editor-in-Chief of this journal.

\section{Additional file}

Additional file 1: Moving image of the CT scan. This study shows

accessory spleen and rotation of the pedicle (arrow).

\section{Abbreviations}

$C T$ : computed tomography; MRI: magnetic resonance imaging; US: ultrasonography.

\section{Competing interests}

The authors declare that they have no competing interests.

\section{Authors' contributions}

$\mathrm{MO}, \mathrm{MA}, \mathrm{Yl}$, and TS underwent the operation. TO and $\mathrm{KH}$ performed some examinations before the operation. NG, KY and $Y N$ made the definite diagnosis. $\mathrm{KU}$ and $\mathrm{FH}$ determined the treatment plan. $\mathrm{KY}$ and $\mathrm{KH}$ create the moving image of the $\mathrm{CT}$ scan. $\mathrm{MO}, \mathrm{MA}, \mathrm{MH}$, and $\mathrm{KU}$ participated in coordination and helped to draft the manuscript. All authors read and approved the final manuscript.

\section{Author details}

'Department of General and Gastroenterological Surgery, Osaka Medical College, 2-7 Daigaku-cho, Takatsuki, Osaka 569-8686, Japan. ${ }^{2}$ Department of Radiology, Osaka Medical College, Takatsuki, Osaka 569-8686, Japan. ${ }^{3}$ Second Department of Internal Medicine, Osaka Medical College, Takatsuki, Osaka 569-8686, Japan.

Received: 1 July 2015 Accepted: 1 October 2015 Published online: 07 October 2015

\section{References}

1. Wadham BM, Adams PB, Johnson MA. Incidence and location of accessory spleens. N Engl J Med. 1981;304(18):1111. Epub 1981/04/30. 
2. Lhuaire M, Sommacale D, Piardi T, Grenier P, Diebold MD, Avisse C, et al. A rare cause of chronic abdominal pain: recurrent sub-torsions of an accessory spleen. J Gastrointest Surg. 2013;17(10):1893-6. Epub 2013/06/14.

3. Grinbaum R, Zamir O, Fields S, Hiller N. Torsion of an accessory spleen. Abdom Imaging. 2006;31(1):110-2. Epub 2005/12/01.

4. Asakuma M, Hayashi M, Komeda K, Shimizu T, Hirokawa F, Miyamoto Y, et al. Impact of single-port cholecystectomy on postoperative pain. $\mathrm{Br} J$ Surg. 2011;98(7):991-5. Epub 2011/05/04.

5. Hayashi M, Asakuma M, Komeda K, Miyamoto Y, Hirokawa F, Tanigawa N. Effectiveness of a surgical glove port for single port surgery. World J Surg. 2010;34(10):2487-9. Epub 2010/08/13.

6. Wacha M, Danis J, Wayand W. Laparoscopic resection of an accessory spleen in a patient with chronic lower abdominal pain. Surg Endosc. 2002;16(8):1242-3. Epub 2002/05/23.

7. Alexander RC, Romanes A. Accessory spleen causing acute attacks of abdominal pain. Lancet. 1914;184:1089-91.

8. Hems TE, Bellringer JF. Torsion of an accessory spleen in an elderly patient. Postgrad Med J. 1990;66(780):838-9. Epub 1990/10/01.

9. Rc A. Accessory spleen with recurring torsion of its pedicle. Lancet. 1929;214:21.

10. Kitchin RJ, Green NA. Torsion of an accessory spleen presenting as acute appendicitis. Br J Surg. 1962;50:232-3. Epub 1962/09/01.

11. Perrine G. Torsion of the accessory splenic pedicle. A case report. Int Surg. 1966;45(2):164-6. Epub 1966/02/01.

12. Bass RT, Yao ST, Freeark RJ. Torsion of an accessory spleen of the cecum presenting as acute appendicitis. N Engl J Med. 1967;277(22):1190-1. Epub 1967/11/30

13. Babcock TL, Coker DD, Haynes JL, Conklin HB. Infarction of an accessory spleen causing an acute abdomen. Am J Surg. 1974;127(3):336-7. Epub 1974/03/01.

14. Onuigbo Wl, Ojukwu JO, Eze WC. Infarction of accessory spleen. J Pediatr Surg. 1978;13(2):129-30. Epub 1978/04/01.

15. Grunspan M, Wechsler U, Weintraub $\mathrm{S}$. Torsion of an accessory spleen simulating acute appendicitis. Isr J Med Sci. 1981;17(6):458-9. Epub 1981/06/01.

16. Seo T, Ito T, Watanabe $Y$, Umeda T. Torsion of an accessory spleen presenting as an acute abdomen with an inflammatory mass. US, CT, and MRI findings. Pediatr Radiol. 1994;24(7):532-4. Epub 1994/01/01.

17. Dahlin LB, Anagnostaki L, Delshammar M, Fork FT, Genell S. Torsion of an accessory spleen in an adult. Case report. Eur J Surg. 1995;161(8):607-9. Epub 1995/08/01.

18. Jans R, Vanslembrouck R, Van Hoe L, Sockx L, Demedts I, Baert AL. Torsion of accessory spleen in an adult patient: imaging findings at $C T, M R I$ and angiography. J Belge Radiol. 1997;80(5):229-30. Epub 1997/12/24.

19. Valls C, Mones L, Guma A, Lopez-Calonge E. Torsion of a wandering accessory spleen: CT findings. Abdom Imaging. 1998;23(2):194-5. Epub 1998/03/28.

20. Padilla D, Ramia JM, Martin J, Pardo R, Cubo T, Hernandez-Calvo J. Acute abdomen due to spontaneous torsion of an accessory spleen. Am J Emerg Med. 1999;17(4):429-30. Epub 1999/08/19.

21. Perez Fontan FJ, Soler R, Santos M, Facio I. Accessory spleen torsion: US, CT and MR findings. Eur Radiol. 2001:11(3):509-12. Epub 2001/04/06.

22. Gardikis S, Pitiakoudis M, Sigalas I, Theocharous E, Simopoulos C. Infarction of an accessory spleen presenting as acute abdomen in a neonate. Eur J pediatr Surg. 2005;15(3):203-5. Epub 2005/07/07.

23. Mendi R, Abramson LP, Pillai SB, Rigsby CK. Evolution of the CT imaging findings of accessory spleen infarction. Pediatr Radiol. 2006;36(12):1319-22. Epub 2006/10/04.

24. Impellizzeri P, Montalto AS, Borruto FA, Antonuccio P, Scalfari G, Arena F, et al. Accessory spleen torsion: rare cause of acute abdomen in children and review of literature. J Pediatr Surg. 2009;44(9):e15-8. Epub 2009/09/09.

25. Yousef $Y$, Cameron BH, Maizlin ZV, Boutross-Tadross O. Laparoscopic excision of infarcted accessory spleen. J Laparoendosc Adv Surg Tech A. 2010;20(3):301-3. Epub 2010/01/12.

26. Ishibashi H, Oshio T, Sogami T, Nii A, Mori H, Shimada M. Torsion of an accessory spleen with situs inversus in a child. J Med Invest. 2012;59 (1-2):220-3. Epub 2012/03/28.

27. Bard V, Goldberg N, Kashtan H. Torsion of a huge accessory spleen in a 20year-old patient. Int J Surg Case Reports. 2014:5(2):67-9. Epub 2014/01/21.

28. Perin A, Cola R, Favretti F. Accessory wandering spleen: report of a case of laparoscopic approach in an asymptomatic patient. Int J Surg Case Reports. 2014;5(12):887-9. Epub 2014/12/03
29. Gayer G, Zissin R, Apter S, Atar E, Portnoy O, Itzchak Y. CT findings in congenital anomalies of the spleen. Br J Radiol. 2001;74(884):767-72. Epub 2001/08/21.

30. Ohta H, Kohno K, Kojima N, Ihara N, Ishigaki T, Todo G, et al. A case of diaphragm hernia containing accessory spleen and great omentum detected by Tc-99m phytate scintigraphy. Ann Nucl Med. 1999;13(5):347-9. Epub 1999/12/03.

\section{Submit your manuscript to a SpringerOpen ${ }^{\circ}$ journal and benefit from:}

- Convenient online submission

- Rigorous peer review

- Immediate publication on acceptance

- Open access: articles freely available online

- High visibility within the field

- Retaining the copyright to your article

Submit your next manuscript at springeropen.com 